\title{
Research on Mechanism Materials of Innovation Performance of Makerspaces
}

\author{
Jiancun Zheng ${ }^{1}$, Lu Shi ${ }^{2}$, Tianhong Jiang ${ }^{1}$ * \\ ${ }^{l}$ Department of Economics and Management, Wenzhou University of Technology, Whenzhou, Zhejiang, \\ China \\ ${ }^{2}$ Department of Business and Management, Wenzhou Vocational College of Science and Technology, \\ Whenzhou, Zhejiang, China \\ *Corresponding Author.
}

\begin{abstract}
The researches of existing makerspaces mainly focus on external factors (policies, resources, etc.) or internal subjects (operating subjects, makers, etc.), but pay little attention to the sustainability and self-running ability of makerspaces themself. In view of this, through theoretical research, this paper combs four operational mechanisms of makerspaces, including platform service, resource aggregation, network connection and endogenous cultural guarantee, and these mechanisms are regarded as the key materials for the innovation output of makerspaces. By empirical analysis to verify the impact of each operational mechanism on the innovation performance, we explore feasible designs of mechanism that is conducive to the sustainable innovation of makerspaces. The result shows that autonomy of service selection, formal network connection and fault-tolerant culture have significant positive effects on the innovation performance of makerspaces, but it will change with the development stage of makerspaces.
\end{abstract}

Keywords: Makerspace, Mechanism material, Operating mechanism, Innovation performance, Network joint mechanism

\section{Introduction}

In recent years, makerspaces have developed rapidly under the impetus of "Double Creation" and have become an important carrier of national innovation and development strategy. According to the data of China Torch Statistical Yearbook in 2019, there are 6,959 places in operation in China in 2018, an increase of 21.3\% compared with 2017, and the scale is in a relatively active development stage. However, through the statistical analysis of the development data of China's makerspaces from 2016 to 2018, this paper finds that the quantity of innovation and entrepreneurship activities (total number of innovation and entrepreneurship activities/total number of resident entrepreneurial teams) of unit team decreased from 0.707 in 2016 to 0.543 in 2018 (as shown in Figure 1), and the quantity of effective intellectual property (total effective intellectual property /total number of resident entrepreneurial teams) of unit team decreased from 0.516 in 2016 to 0.466 in 2018 (as shown in Figure 2). This phenomenon has also been confirmed in some existing studies [1-3]. Therefore, it is of great significance to explore how to "intensively cultivate" the existing makerspaces. 


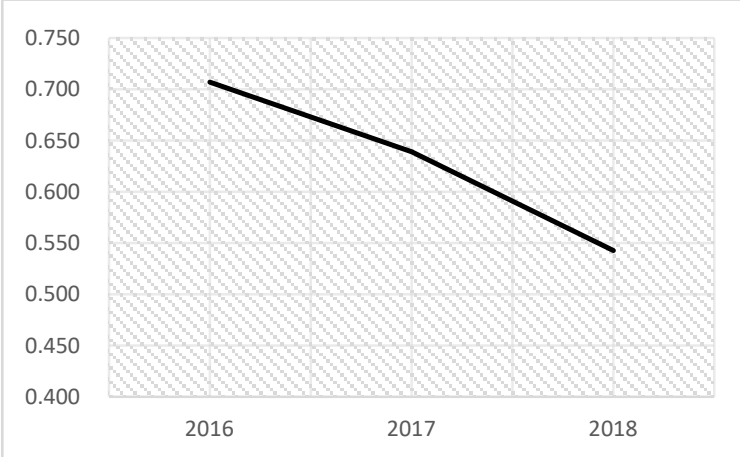

Figure 1 Quantity of innovation and entrepreneurship activities of unit team Data source: China Torch Statistics Yearbook 2017-2019.

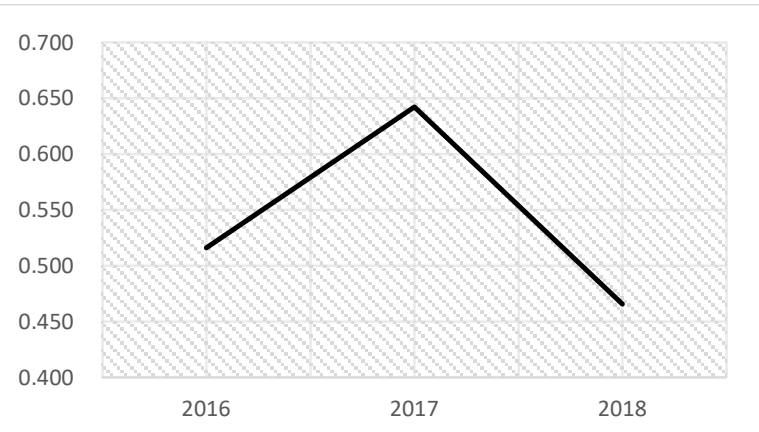

Figure 2 Quantity of effective intellectual property of unit team Data source: China Torch Statistics Yearbook 2017-2019.

The existing research and discussion on innovation efficiency of makerspaces mainly focuses on the external factors and internal participants of makerspaces. Among them, external factors such as government policy support, financing channels, human resources (entrepreneurial instructors), etc. [4,5], and the internal participants mainly involve the main characteristics of operators of makerspaces [6], and the intrinsic motivation of Makers [7]. However, discussions on the internal mechanism of sustainable self-operation of makerspaces are relatively scarce [8]. From the perspective of ecosystem, makerspace, as an entrepreneurial ecosystem, will inevitably generate entropy in its evolution and development, which will lead to chaos and disorder. It is necessary to establish a corresponding governance mechanism to introduce negative entropy from the outside to promote order [9]. Therefore, a reasonable mechanism design is a necessary condition to ensure the sustainable innovation of makerspaces.

The purpose of this paper is to systematically sort out the main operating mechanisms of makerspaces through theoretical research, and to verify the impact of each operating mechanism on innovation performance by empirical research, so as to explore sustainable innovation of makerspaces from the perspective of mechanism design.

\section{Theoretical Analysis and Research Hypothesis}

\subsection{Platform service mechanism}

The platform service function refers to the infrastructure, supporting services, operation management, etc., which is the basis for the normal operation of the makerspaces [10], and its completeness and high quality greatly affect the incubation effect and entrepreneurial success rate of entrepreneurs [11]. However, these platform service functions of makerspaces, including market, finance, support system, human resources, etc., are not all naturally generated, but need to be gradually formed through conscious artificial design [9]. Therefore, it is of fundamental and important significance to establish a perfect service mechanism and promote the formation of the space service 
function. Existing researches suggest that the poor innovation effect of makerspaces may be caused by mismatch between the service function provided by makerspaces and the demand of makers [12], or by the limitation that makerspaces rely on their own resources to provide all services [13]. In view of this, the introduction of marketoriented mechanism to realize the the transformation of platform matching mechanism from what is provided to what is needed. That will be beneficial to the improvement of the efficiency of makerspaces' innovation [14]. Therefore, this paper puts forward the following assumptions:

H1: The more perfect basic service function is beneficial to innovation performance of makerspaces.

$\mathrm{H} 2$ : The stronger the self-matching basic service function mechanism is, the more beneficial it is to innovation performance of makerspaces.

\subsection{Resource aggregation mechanism}

Policy, capital, technology, manpower and other resource elements are necessary conditions in innovation and entrepreneurship activities. However, they are also bottleneck obstacles that most makers cannot avoid in entrepreneurship [15]. The ability to gather makers in makerspaces is also based on such entrepreneurial needs [16]. Therefore, makerspaces need to have the ability to gather resources. On the one hand, makerspaces should become landmark zone for innovation and entrepreneurship, releasing a strong and easily recognizable entrepreneurial signal and reducing the search cost of social resources for entrepreneurial projects [10]. On the other hand, they should establish an efficient resource absorption mechanism to reduce the inflow resistance of resources and make makerspaces the low-lying areas for resources to rush into [17]. In addition, the makerspaces themself also need to solve the docking problem between innovation and entrepreneurship activities and the required resources [18], especially the integration of strategic knowledge and technical resources, and the integration of resources and maker's commercial operation ability [10], so as to form a stable and orderly internal flow mechanism to integrate resources. Therefore, this paper puts forward the following assumptions:

H3: The better the resource pooling mechanism is, the more beneficial it is to innovation performance of makerspaces.

H4: The mechanism of integrating heterogeneous resources has a positive impact on innovation performance of makerspaces.

\subsection{Network connection mechanism}

Makerspaces are consortia composed of many makers and various entrepreneurial resource providers, and the network relationship among these participants constitutes the internal connection of makerspaces [10]. Through these connections, the circulation of resources, information and energy needed for innovation and entrepreneurship can be internalized, thus greatly reducing transaction costs [19], and that will improve the success rate of innovation. According to the existing research, it is a formal internal network connection that can promote the exchange of knowledge, technology and experience, and improve the innovation performance. Building a cooperative team of collaborative governance among all subjects in makerspaces [9], or accomplishing the project together through the division of tasks [8], are considered to be such formal connections. In addition, informal contacts based on non-trading activities, such as experience forum, tea party and cross-organizational league building, are also considered to be beneficial to trust building and information exchange among subjects in the makerspaces, and have a positive effect on innovation performance [20]. Therefore, this paper puts forward the following assumptions:

H5: The formal internal network connection mechanism has a positive impact on innovation performance of makerspaces. 
H6: Informal internal network connection mechanism has a positive impact on innovation performance of makerspaces.

\subsection{Endogenous culture guarantee mechanism}

Makerspaces are essentially regarded as sharing of tools, technologies and governance methods [21]. Makers in makerspaces need to promote each other through sharing creativity, knowledge and achievements [22]. Therefore, establishing an open mechanism for sharing and exchanging achievements is as important as hardware service support and resources, that can entrepreneurial spirit and energy be truly transmitted in makerspaces [23]. In addition, makerspace, as a kind of "slow inspiration", usually needs to go through a long incubation period before it can develop, and only an inclusive cultural environment can encourage makers to face various uncertainties with confidence [24]. Therefore, it is necessary to create a cultural atmosphere that is tolerant of trial and failure in makerspaces [15,25]. Environmental support encouraged by mutual assistance can empower innovation activities [26]. Therefore, this paper puts forward the following assumptions:

H7: The internal achievement sharing mechanism has a positive impact on innovation performance of makerspaces.

H8: The culture of fault tolerance-trial and error has a positive impact on the innovation performance of makerspaces.

\section{Research Design}

\subsection{Sample selection and data source}

According to the data of China Torch Statistical Yearbook, the eastern part of China is the most concentrated place in distribution of makerspaces, accounting for nearly $50 \%$ of the total, which can basically reflect the current development level of China's makerspaces. Therefore, this paper chooses Zhejiang Province in the east as the research sample region, distributes 120 questionnaires, recovers 84. By eliminating incomplete questionnaires, we obtain 63 valid questionnaires.

\subsection{Variable interpretation}

At present, there is still a lack of uniform standards for the operation performance evaluation of makerspaces, and the evaluation indicators adopted by different scholars are quite different. However, one thing is generally consistent, that is, makerspaces are comprehensive carriers integrating theoretical innovation, institutional innovation, service innovation, cultural innovation and technological innovation [27], and innovation performance is the most critical result of makerspaces operation. Most scholars regard the amount of intellectual property rights acquired by enterprises/teams as an important index for evaluating the innovation performance in makerspaces $[28,29]$. Therefore, this paper sets the quantity of intellectual property rights (QIP) obtained by enterprises/teams in makerspaces to evaluate the creative performance as the dependent variable.

In this paper, the index setting and interpretation of independent variables are shown in the following table:

Table 1 Index setting and interpretation of independent variables

\begin{tabular}{c|c|c|c}
\hline $\begin{array}{c}\text { Operating } \\
\text { mechanisms }\end{array}$ & Variable & $\begin{array}{c}\text { Variable } \\
\text { abbreviation }\end{array}$ & Variable description \\
\hline $\begin{array}{c}\text { Platform service } \\
\text { mechanism }\end{array}$ & $\begin{array}{c}\text { Number of } \\
\text { service functions }\end{array}$ & NSF & $\begin{array}{l}\text { The quantity of services that makerspaces can provide to } \\
\text { the settled enterprises/teams besides office space } \\
\text { services. }\end{array}$ \\
\hline
\end{tabular}

ISSN: 0010-8189

(C) CONVERTER 2020 


\begin{tabular}{|c|c|c|c|}
\hline & $\begin{array}{c}\text { Autonomy of } \\
\text { service selection }\end{array}$ & ASS & $\begin{array}{l}\text { When the services provided by makerspaces only have a } \\
\text { single source, the choice autonomy is regarded as } 0, \\
\text { multi-source without integration is regarded as } 1 \text {, } \\
\text { structure an open platform for makers to match and } \\
\text { choose is } 2 \text {. }\end{array}$ \\
\hline \multirow[b]{2}{*}{$\begin{array}{l}\text { Resource } \\
\text { aggregation } \\
\text { mechanism }\end{array}$} & $\begin{array}{l}\text { Resource } \\
\text { collection } \\
\text { channel }\end{array}$ & $\mathrm{RCC}$ & $\begin{array}{l}\text { The number of the below three items: Construction of } \\
\text { declaration channel for normalized government policy, } \\
\text { organization of knowledge lectures or training about } \\
\text { development of entrepreneurship, Building project } \\
\text { financing channel or organizing roadshow. }\end{array}$ \\
\hline & $\begin{array}{l}\text { Heterogeneous } \\
\text { resource } \\
\text { integration }\end{array}$ & HRI & $\begin{array}{l}\text { In addition to providing funds, whether investors provide } \\
\text { other guidance and support, such as management: } \\
\text { organizing investors to carry out extensive guidance } \\
\text { about enterprise development planning and management } \\
\text { to all the makers, it is regarded as } 1 \text {. Organize investors } \\
\text { to provide strategic management guidance for those who } \\
\text { have already been invested, it is regarded as } 2 \text {, no } \\
\text { relevant arrangement is } 0 \text {. }\end{array}$ \\
\hline \multirow{2}{*}{$\begin{array}{l}\text { Network connection } \\
\text { mechanism }\end{array}$} & $\begin{array}{l}\text { Formal } \\
\text { connection }\end{array}$ & $\mathrm{FC}$ & $\begin{array}{l}\text { It is } 1 \text { to formally establish business cooperation between } \\
\text { different makers or to form a common governance } \\
\text { decision-making team, and it is } 0 \text { if it is not. }\end{array}$ \\
\hline & $\begin{array}{l}\text { Informal } \\
\text { connection }\end{array}$ & IC & $\begin{array}{l}\text { Those who promote the exchange and interaction } \\
\text { between different subjects by building maker exchange } \\
\text { places, organizing discussion tea parties, group activities, } \\
\text { etc. are } 1 \text {, and it is } 0 \text { if it is not. }\end{array}$ \\
\hline \multirow{2}{*}{$\begin{array}{l}\text { Endogenous culture } \\
\text { guarantee } \\
\text { mechanism }\end{array}$} & $\begin{array}{l}\text { Achievement } \\
\text { sharing culture }\end{array}$ & ASC & $\begin{array}{l}\text { The exchange of achievements in technological } \\
\text { innovation methods, enterprise management experience } \\
\text { and entrepreneurial experience between enterprises/teams } \\
\text { in a normalized organization is } 1 \text {, and none is } 0 \text {. }\end{array}$ \\
\hline & $\begin{array}{l}\text { Fault-tolerant } \\
\text { culture }\end{array}$ & $\mathrm{TE}$ & $\begin{array}{l}\text { Providing assistance in the form of innovation failure } \\
\text { subsidy, reducing rent and service fee, or introducing } \\
\text { venture capital, for makers who failed in innovation and } \\
\text { entrepreneurship, is regarded as } 1 \text {, and if not, it is } 0 \text {. }\end{array}$ \\
\hline
\end{tabular}

In this paper, multiple linear regression method is used to test the influence of each operation mechanism on innovation performance of makerspaces. Considering that with the extension of the operation time of makerspaces, the longer an enterprise operates, the more likely it is to produce more benefits. In order to improve the accuracy of regression model and reduce the possibility of other explanations of results, this study introduced the age of makerspace as the control variable (AGE).

\section{Empirical Results and Analysis}

\subsection{Model testing}

Through SPSS analysis of the model, we can find that the goodness of fit of the model is good. The R2 value of 0.875 indicates that independent variable can explain the overall situation by $87.5 \%$, and the equation is ideal. Meanwhile, the D-W test statistic is 2.974 , which is close to 2, indicating that there is no autocorrelation problem. Secondly, the $\mathrm{F}$ test results in Table 4 show that the probability $\mathrm{P}$ value is 0.000 , and when the significance level is 0.05 , the original assumption that the overall regression coefficient is 0 can be significantly rejected, that is, there is a linear relationship between the dependent variable and the independent variable.

Table 2 Model summary ${ }^{\mathrm{b}}$

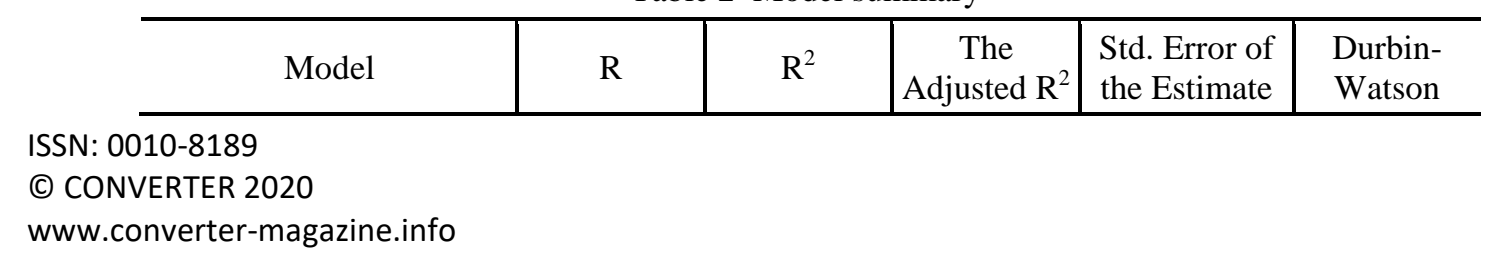




\begin{tabular}{l|l|l|l|l|l}
1 & $.935^{\mathrm{a}}$ & 0.875 & .856 & 8.689 & 2.974 \\
\hline
\end{tabular}

a. Predictive Variable: (Constant), TE, NSF, ASC, ASS, AGE, HRI, FC, RCC。

Table $3 \mathrm{~F}$ test $\left(\right.$ Anova $\left.^{\mathrm{b}}\right)$

\begin{tabular}{c|l|c|c|c|c|c}
\hline \multicolumn{2}{c|}{ Model } & $\begin{array}{c}\text { The Sum of } \\
\text { Squares }\end{array}$ & df & $\begin{array}{c}\text { Mean } \\
\text { Square }\end{array}$ & F & Sig. \\
\hline \multirow{4}{*}{} & Regression & 28520.362 & 8 & 3565.045 & 47.218 & $.000^{\mathrm{a}}$ \\
\cline { 2 - 7 } & Residual & 4077.067 & 54 & 75.501 & & \\
\cline { 2 - 8 } & The Total & 32597.429 & 62 & & & \\
\hline
\end{tabular}

a. Predictive Variable: (Constant), TE, NSF, ASC, ASS, AGE, HRI, FC, RCC。

b. Dependent Variable: QIP

Data Resource: SPSS 19.0 software.

According to the collinearity statistics in Table 4, it can be found that the variance expansion factor (VIF) is far less than 10. Therefore, it is considered that there is basically no collinearity between independent variables.

Table 4 Collinearity Test

\begin{tabular}{c|c|c|c|c|c|c|c|c|c|c}
\hline \multicolumn{2}{l|}{} & (Constant) & AGE & NSF & ASS & RCC & HRI & FC & ASC & TE \\
\hline $\begin{array}{c}\text { Collinearity } \\
\text { Statistics }\end{array}$ & Tolerance & & 0.555 & 0.511 & 0.398 & 0.202 & 0.527 & 0.202 & 0.592 & 0.408 \\
\cline { 2 - 10 } & VIF & & 1.803 & 1.959 & 2.511 & 4.961 & 1.899 & 4.939 & 1.689 & 2.451 \\
\hline
\end{tabular}

Data Resource: SPSS 19.0 software.

\subsection{Regression analysis and hypothesis testing}

Regression analysis was carried out by SPSS software, and the results are shown in Table 5. Model 1 is a model with only control variables. The results show that although the goodness of fit of the equation model established by AGE and dependent variable QIP is not ideal, AGE has a significant impact on QIP, that is, the continuous operation time of makerspaces has a significant impact on the innovation performance of makerspaces.

Table 5 Results of model regression test

\begin{tabular}{c|c|c}
\hline \multirow{2}{*}{ Independent Variable } & \multicolumn{2}{|c}{ Dependent Variable (QIP) } \\
\cline { 2 - 3 } & Model 1 & Model 2 \\
\hline (Constant) & $-18.391^{* *}$ & $-20.436^{*}$ \\
\hline AGE & $12.232^{* * *}$ & $3.904^{*}$ \\
\hline NSF & & -0.513 \\
\hline ASS & & $20.586^{* * *}$ \\
\hline RCC & & -2.198 \\
\hline HRI & & 0.511 \\
\hline FC & & $23.313^{* * *}$ \\
\hline ASC & & -10.011 \\
\hline TE & 0.247 & $11.53^{* *}$ \\
\hline R & 20.032 & 0.875 \\
\hline F & 0 & 47.218 \\
\hline P value & & 0 \\
\hline Notes $*$ means $\mathrm{p}$ value $<0.05 * *$ means $\mathrm{p}$ value $<0.01 * * *$ means $\mathrm{p}$ value $<0.001$
\end{tabular}

Notes: $*$ means $\mathrm{p}$ value $<0.05, * *$ means $\mathrm{p}$ value $<0.01, * * *$ means $\mathrm{p}$ value $<0.001$

Data Resource: SPSS 19.0 software.

Model 2 introduces explanatory variables that need to be observed in this study on the basis of control variable.

ISSN: 0010-8189 
According to the statistical results in Table 6, the model has a good goodness of fit, and the results of F test are remarkable, indicating that the equation can better explain the relationship between dependent variables and explanatory variables. It can be seen from the data that the autonomy of service selection (ASS), formal network connection mechanism (FC) and fault-tolerant culture (TE) have significant positive effects on innovation performance (QIP), while the number of service functions (NSF), resource pooling channel (RCC), heterogeneous resource integration (HRI) and achievement sharing culture (ASC) have no significant positive effects on innovation performance. Therefore, the verification results of all assumptions are summarized as follows:

Table 6 The test results of hypotheses

\begin{tabular}{l|c}
\hline \multicolumn{1}{c|}{ Hypotheses } & Result \\
\hline $\begin{array}{l}\text { H1: The more perfect basic service function is beneficial to innovation performance of } \\
\text { makerspaces. }\end{array}$ & Nonsupport \\
\hline $\begin{array}{l}\text { H2: The stronger the self-matching basic service function mechanism is, the more beneficial it is to } \\
\text { innovation performance of makerspaces. }\end{array}$ & Support \\
\hline $\begin{array}{l}\text { H3: The better the resource pooling mechanism is, the more beneficial it is to innovation } \\
\text { performance of makerspaces. }\end{array}$ & Nonsupport \\
$\begin{array}{l}\text { H4: The mechanism of integrating heterogeneous resources has a positive impact on innovation } \\
\text { performance of makerspaces. }\end{array}$ & Nonsupport \\
$\begin{array}{l}\text { H5: The formal internal network connection mechanism has a positive impact on innovation } \\
\text { performance of makerspaces. }\end{array}$ & Support \\
$\begin{array}{l}\text { H6: Informal internal network connection mechanism has a positive impact on innovation } \\
\text { performance of makerspaces. }\end{array}$ & Nonsupport \\
$\begin{array}{l}\text { H7: The internal achievement sharing mechanism has a positive impact on innovation performance } \\
\text { of makerspaces. }\end{array}$ & Nonsupport \\
\hline $\begin{array}{l}\text { H8: The culture of fault tolerance-trial and error has a positive impact on the innovation } \\
\text { performance of makerspaces. }\end{array}$ & Support \\
\hline
\end{tabular}

Data Resource: author arranged.

\subsection{The Influence of Continuous Operation Time (AGE) on Innovation Performance}

According to the results of Model 1, the continuous operation time of makerspaces has a significant impact on their innovation performance. Some scholars in previous studies also believe that makerspaces follow the general law of organizational life cycle evolution [30]. And makerspaces have different characteristics at different stages, so it is necessary to adopt different strategies and policies at different stages [31]. Therefore, based on the original analysis model, this paper divides the sample into two sub-samples according to the continuous operation time (AGE), namely, the makerspaces with the operation time of 3 years or less (model 3) and makerspaces with the operation time of more than 3 years (model 4), and eliminates the control variable (AGE) based on the original regression model for further analysis and verification. Considering that the quantity of each sub-sample is relatively small after splitting, in order to find the relationship between explanatory variables and dependent variables with the best regression equation as far as possible, the stepwise regression method is adopted in the test of these two models.

As shown in Table 8, under Model 3, which focus on makerspaces with operating time of 3 years or less, autonomy of service selection (ASS), formal network connection mechanism (FC) and fault-tolerant culture (TE) have significant positive effects on innovation performance (QIP) of makerspaces. However, under Model 4, which focus on makerspaces with operating time of more than 3 years, Only formal network connection mechanism (FC) has a significant positive impact on innovation performance (QIP).

Table 7 Regression test results of two sub-samples with different operating time

\begin{tabular}{l|c|c}
\hline \multirow{2}{*}{ Independent Variable } & \multicolumn{2}{|c}{ Dependent Variable (QIP) } \\
\cline { 2 - 3 } & Model 3 & Model 4 \\
\hline
\end{tabular}




\begin{tabular}{c|c|c} 
(Constant) & $-23.983^{* * *}$ & 6.5 \\
\hline NSF & & \\
\hline ASS & $27.733^{* * *}$ & \\
\hline RCC & & \\
\hline HRI & $11.733^{* *}$ & $43.500 * * *$ \\
\hline FC & & \\
\hline ASC & $14.600^{* * *}$ & 0.81 \\
\hline TE & 0.878 & 68.132 \\
\hline $\mathrm{R}^{2}$ & 72.128 & 0 \\
\hline F & 0 & \\
\hline P value & & \\
\hline
\end{tabular}

Notes: * means $\mathrm{p}$ value $<0.05, * *$ means $\mathrm{p}$ value $<0.01, * * *$ means $\mathrm{p}$ value $<0.001$

Data Resource: SPSS 19.0 software.

\section{Main Conclusions and Enlightenment}

The main purpose of this paper is to discuss the mechanism design that is helpful to the sustainable innovation of makerspaces. Through theoretical analysis and combing of existing research, this paper refines four main operating mechanisms. They are platform service, resource aggregation, network connection and endogenous culture guarantee. On this basis, we set eight measurement dimensions: number of service functions, autonomy of service selection, resource collection channel, heterogeneous resource integration, formal connection, informal connection, achievement sharing culture and fault-tolerant culture. By taking 63 makerspaces in Zhejiang province of China as samples, the hypotheses are tested and some conclusions are drawn as follows:

First, only by providing service functions that match the needs of start-ups and teams can we contribute to sustainable innovation of makerspaces. At present, most makerspaces pay attention to the supply of diversified service functions (our survey statistics shows that more than $81 \%$ of makerspaces provide more than five service functions), but there is a big difference in the attention to whether the service functions provided match the demands, which leads to the difference of innovation performance.

Second, constructing a formal network connection mechanism with substantive and in-depth communication is a necessary condition for promoting sustainable innovation of makerspaces. Currently, makerspaces are keen on organizing tea party, group interaction and other informal communication links, which may not have a significant positive impact on their innovation performance. It should focus on the establishment of formal network relationships such as "task contact for jointly completing projects" and "contractual joint governance team".

Third, the cultural atmosphere of encouraging innovation, tolerating error and failure is an important endogenous cultural guarantee for sustainable innovation in makerspaces. The popular pursuit of successful culture is a positive attitude expression to make people's life better. However, makerspaces are the places which foster fire and hatches seeds, it is necessary to create values that respect the courage of trial-and-error, and encourage innovation.

Last, in different periods of their development, makerspaces have different requirements for the design of operation mechanism. For the newly established ones, effective service functions, reliable formal network connection and the fault-tolerant culture can promote the positive innovation. For the makerspaces which have accumulated a certain development time, the substantive cooperation and communication brought by the formal network connection between makers is an indispensable condition for sustainable innovation. Therefore, during the development of makerspaces, the design of operation mechanism should not be static, but should be dynamically adjusted.

\section{References}


[1] Z.Y. Huang, H. Zhao, Y.N. Xu, "Study on the synergistic effect of influencing factors of innovation output of makerspaces —ualitative comparative analysis of fuzzy sets based on data of makerspaces in 31 provinces and cities," Scientific Research Management (in Chinese), vol. 41, no. 5, pp. 21-31, 2020.

[2] M.M. Gao, D. Zhu, "evaluation of operation efficiency of makerspaces in China-based on PP-SFA model," contemporary economics (in Chinese), no. 11, pp. 47-51, 2020.

[3] X.H. Liu, D.H. Wang, M.G. Meng, et al., "Research on innovation efficiency of domestic makerspaces based on three-stage data envelopment analysis," Science and Technology Management Research (in Chinese), vol. 40, no. 20, pp. 64-74, 2020.

[4] H.L. Cui, S. Lv, "'Multi-dimensional Cooperation, One Body and Two Wings', Research on Innovation Model of Makerspaces," Macroeconomic Research (in Chinese), no. 7, pp. 87-96, 2020.

[5] Z. M'chirgui, W. Lamine, S. Mian, et al., "University technology commercialization through new venture projects: an assessment of the French regional incubator program," The Journal of Technology Transfer, vol. 43. pp. 1142-1160, 2018.

[6] A.M.L. Davis, "Current trends and goals in the development of makerspaces at New England College and Research Libraries," Information Technology and Libraries, vol. 37, no. 2, pp. 94, 2018.

[7] S.Y. Han, J. Yoo, H. Zo, et al.," Understanding makerspace continuance: A self-determination perspective," Telematics \& Informatics, vol. 34, no. 4, pp. 184-195, 2017.

[8] L.M. Ren, "Functional development and endogenous cultural requirements of makerspaces in China," Academic Forum (in Chinese), vol. 40, no. 4, pp. 136-141, 2017.

[9] Y.L. Zhang, F. Bai, "Research on the evolution and optimization of makerspace based on dissipation theory," Science and Science and Technology Management (in Chinese), vol. 38, no. 1, pp. 22-29, 2017.

[10] S. Chen, L.Y. Xiang, R.J. Yu, "Entrepreneurship ecosystem of makerspaces: characteristics, structure, mechanism and strategy-taking Hangzhou dream town as an example," business economy and management (in Chinese), no. 11, pp. 35-43, 2015.

[11] C. Liu, "Research and empirical analysis on the operation mode of makerspace," Hubei University, 2017.

[12] X.F. Xie, Q.L. Liu, "The ecological model of makerspaces in the era of 2.0, Comparison and enlightenment at home and abroad," Scientific Research (in Chinese), vol. 36, no. 4, pp. 577-585, 2018.

[13] X.Y. Li, "Research on the operation mechanism of entrepreneurship platform of makerspaces in Sanya City," Regional Economy (in Chinese), vol. 546, no. 10, pp. 31-33, 2016.

[14] J.X. Wang, F. Tian, Y. Sheng, "Research on the positioning of makerspace and the evolution logic of its development strategy, taking Ali Baichuan as an example," Science and Technology Progress and Countermeasures (in Chinese), vol. 33, no. 11, pp. 1-6, 2016.

[15] J. Wu, Y.L. Zhan, H.S. Zhou, "Theoretical interpretation and countermeasures of makerspaces," Science and Technology Management Research(in Chinese), vol. 36, no. 13, pp. 37-41, 2016.

[16] Z.Y. Liu, S.P. Cao, S.Q. Liao, "Research on the influencing factors of maker agglomeration of makerspaces, based on questionnaire and in-depth interview analysis," Journal of South China University of Technology: Social Science Edition(in Chinese), vol. 104, no. 4, pp. 62-70, 2018.

[17] Q. Wang, "The construction of entrepreneurship ecosystem of makerspaces, "Enterprise Economy(in Chinese), no. 10, pp. 5-9, 2016.

[18] Cacciatori, E.D. Tamoschus, G.Grabher, "Knowledge transfer across projects: codification in creative, high-tech and engineering industries," Management Learning, vol. 43, no. 3, pp. 309-331, 2012.

[19] Letizia Mortaraa, Nicolas Gontran Parisotb, "Through entrepreneurs' eyes: the Fab-spaces constellation," International Journal of Production Research, vol. 54, no. 23, pp. 7158-7180, 2016.

[20] W. Ni, "Research on the network connection mechanism and performance of enterprise collaborative innovation from the perspective of social capital," Xidian University, 2009.

[21] D. Kera, "Nanosmano lab in Ljubljana: disruptive prototypes and experimental governance of nanotech nologies in the hackerspaces," Journal of Science Communication, vol. 11, no. 4, pp. 37-49, 2012. 
[22] N.R. Irie, Y.C. Hsu, Y.H. Ching, "Makerspaces in diverse places: a comparative analysis of distinctive national discourses surrounding the maker movement and education in four countries," TechTrends, vol. 63, no. 4, pp. 397-407, 2019.

[23] C. Dai, L.G. Ni, "Research on the composition and development path of makerspaces based on entrepreneurial ecosystem," Journal of changchun university of science and technology (Social Science Edition), vol. 28, no. 12, pp. 77-80, 2015.

[24] Holm, E.J. Van, "Makerspaces and contributions to entrepreneurship," Procedia - Social and Behavioral Sciences, vol. 195, pp. 24-31, 2015.

[25] T.M. Jia, L.H. Lei, M.N. Wang, "Makerspace ecosystem: connotation, characteristics, structure and operation mechanism," Science and Technology Management Research (in Chinese), vol. 37, no. 11, pp. 8-14, 2017.

[26] S. Prendeville, G. Hartung, C. Brass, et al., "Circular makerspaces: the founder's view," International Journal of Sustainable Engineering, no. 1, pp. 1-17, 2017.

[27] Y. Tian, Z.G. Tian, Y.J. Zhao, "The impact of collaborative innovation of creative spatial intellectual capital on innovation performance of makers from the perspective of H-S-R three-dimensional structure," Scientific and Technological Progress and Countermeasures (in Chinese), vol. 35, no. 8, pp. 15-23, 2018.

[28] J.J.Bao, "Research on the Influence of Entrepreneurial Environment on Entrepreneurial Performance of makerspace," Hebei University of Economics and Business, 2018.

[29] J.Tian, X.X.Yin, "Operation efficiency and correlation analysis of makerspaces based on provincial data," Journal of Jiangsu University of Science and Technology (Social Science Edition), vol. 19, no. 2, pp. 82-87, 2019.

[30] J.G. Liu, "The ecological mechanism of government and market participating in the creation of makerspace-based on the evidence of 52 municipal administrative regions in China," East China Economic Management (in Chinese), vol. 32, no. 7, pp. 55-64, 2018.

[31] F. Bai, "Research on entrepreneurial ecosystem based on life cycle theory," Modern Management Science (in Chinese), no. 12, pp. 52-54, 2015. 